\title{
BMJ Open Cardiovascular health knowledge, attitude and practice/behaviour in an urbanising community of Nepal: a population-based cross-sectional study from Jhaukhel-Duwakot Health Demographic Surveillance Site
}

\author{
Abhinav Vaidya, ${ }^{1,2}$ Umesh Raj Aryal, ${ }^{1,2}$ Alexandra Krettek ${ }^{2,3}$
}

To cite: Vaidya A, Aryal UR, Krettek A. Cardiovascular health knowledge, attitude and practice/behaviour in an urbanising community of Nepal: a population-based cross-sectional study from Jhaukhel-Duwakot Health Demographic Surveillance Site. BMJ Open 2013;3: e002976. doi:10.1136/ bmjopen-2013-002976

- Prepublication history and additional material for this paper is available online. To view these files please visit the journal online (http://dx.doi.org/10.1136/ bmjopen-2013-002976).

Received 30 March 2013 Revised 7 August 2013 Accepted 2 October 2013

CrossMark

For numbered affiliations see end of article.

Correspondence to Dr Abhinav Vaidya; Abhinav.Vaidya@nhv.se

\section{ABSTRACT}

Objectives: This study determined the knowledge, attitude and practice/behaviour of cardiovascular health in residents of a semiurban community of Nepal.

Design: To increase the understanding of knowledge, attitude and practice/behaviour towards cardiovascular health, we conducted in-home interviews using a questionnaire based on the WHO STEPwise approach to surveillance and other resources, scoring all responses. We also recorded blood pressure and took anthropometric measurements.

Setting: Our study was conducted as part of the Heart-Health-Associated Research and Dissemination in the Community project in the Jhaukhel-Duwakot Health Demographic Surveillance Site in two urbanising villages near Kathmandu.

Participants: The study population included 777 respondents from six randomly selected clusters in both villages.

Results: Seventy per cent of all participants were women and $26.9 \%$ lacked formal education. The burden of cardiovascular risk factors was high; $20.1 \%$ were current smokers, $43.3 \%$ exhibited low physical activity and $21.6 \%$ were hypertensive. Participants showed only poor knowledge of heart disease causes; $29.7 \%$ identified hypertension and $11 \%$ identified overweight and physical activity as causes, whereas only $2.2 \%$ identified high blood sugar as causative. Around $60 \%$ of respondents did not know any heart attack symptoms compared with $20 \%$ who knew 2-4 symptoms. Median percentage scores for knowledge, attitude and practice/behaviour were $79.3,74.3$ and 48 , respectively. Nearly $44 \%$ of respondents had insufficient knowledge and less than $20 \%$ had highly satisfactory knowledge. Among those with highly satisfactory knowledge, only $14.7 \%$ had a highly satisfactory attitude and $19.5 \%$ and $13.9 \%$ had satisfactory and highly satisfactory practices, respectively.

Conclusions: Our study demonstrates a gap between cardiovascular health knowledge, attitude and practice/ behaviour in a semiurban community in a low-income nation, even among those already affected by cardiovascular disease.

\section{ARTICLE SUMMARY}

Strengths and limitations of this study

- This study is the first to extensively explore knowledge, attitude and behaviour/practice regarding cardiovascular health in Nepal and was conducted in a health demographic surveillance site which provides the logistic advantage of further follow-up and intervention.

- Using prompted and unprompted questions in the same study illustrates the variation that may be obtained by these approaches.

- Unintentional oversampling of women respondents yielded unsegregated gender-wise results that are more likely to represent knowledge, attitude and practice/behaviour in women.

\section{INTRODUCTION}

Non-communicable diseases (NCDs) pose increasingly important public health problems in low-income and middle-income countries (LMICs). In 2008, $80 \%$ of global NCD deaths occurred in LMICs; ${ }^{1}$ NCDs recently accounted for 7.9 million of 14.5 million deaths (54\%) in Southeast Asia $^{2}$ and were responsible for two of every three deaths (34.5 million) worldwide in $2010 .^{3}$ Poverty, illiteracy, poor-health infrastructure and demographic transition, including increasing life expectancy, are major contributors to the rising burden of NCDs in LMICs. Other postulated causes include poor fetal and childhood nutrition. ${ }^{4} 5 \mathrm{~A}$ similar pattern is evident in South Asian countries like Nepal, where NCDs currently occur more frequently than communicable diseases and behavioural risk factors such as tobacco smoking are high. ${ }^{6}$ 
Globally, cardiovascular diseases (CVDs) are responsible for one in four deaths (12.9 million). ${ }^{3}$ Eighty per cent of CVDs result from tobacco smoking, unhealthy diet, physical inactivity and harmful use of alcohol. ${ }^{7}$ The risk of allcause mortality among individuals who score poorly in behavioural factors is fourfold higher than in those who score best. ${ }^{8}$ In high-income countries, declining CVD mortality is largely attributed to the reduction of behavioural risk factors. ${ }^{9}$ Underlying socioeconomic parameters and societal influences affect exposure and vulnerability to CVD risk factors. Therefore, surveillance of NCD risk factors should include social determinants of cardiovascular health. ${ }^{10}$ Currently, understanding the individual and social determinants of cardiovascular health behaviours is among the top 20 priority areas for NCD research in LMICs. $^{11}$

As a precursor of favourable health behaviour, experts have advocated health literacy since community-based interventions began exploring the potential impact of behavioural changes on CVD. ${ }^{12}$ The WHO promotes public awareness of diet and physical activity as a 'best buy' to improve cardiovascular behaviour. ${ }^{9}$ However, achieving the desired health behaviour requires a deeper understanding of the underlying social context of disease. ${ }^{13} 14$ Hence, studies on knowledge, attitude and practice (KAP) increase our understanding of cardiovascular health literacy and community behaviour. ${ }^{15}$ Currently, such studies have been limited in South Asia.

Earlier studies report low levels of knowledge about heart attack $^{16}$ and diabetes symptoms in Nepal. ${ }^{17}$ Nepal's high prevalence of underlying behavioural risk factors, particularly tobacco and alcohol consumption and poor cardiovascular health knowledge, is a matter of concern. ${ }^{18}$ Nationwide in Nepal, the age group $25+$ exhibits fasting blood glucose of $5.5 \mathrm{mmol} / \mathrm{L}$ for men and $5.4 \mathrm{mmol} / \mathrm{L}$ for women, systolic blood pressure of $125.9 \mathrm{~mm} \mathrm{Hg}$ and $126.6 \mathrm{~mm} \mathrm{Hg}$ for men and women, respectively, and total cholesterol of $4.1 \mathrm{mmol} / \mathrm{L}$ (men) and $4.3 \mathrm{mmol} / \mathrm{L}$ (women). ${ }^{19}$

Currently, attempts to improve cardiovascular health knowledge and behaviour in Nepal focus mainly on campaigns that transmit information but pay little attention to the population's actual health literacy. We therefore undertook a community-based KAP study in the Jhaukhel-Duwakot Health-Demographic Surveillance Site (JD-HDSS) outside Kathmandu where NCDs, particularly CVDs, are the predominant cause of morbidity and mortality. ${ }^{20}$ Additionally, our pilot study in the Duwakot population demonstrated poor cardiovascular health knowledge. ${ }^{21}$ Our study is part of the Heart-Health Associated Research and Dissemination in the Community (HARDIC) project, which is the cardiovascular health component of JD-HDSS. In Nepalese, hardic means 'heartily' or 'from the heart'. This paper reports the baseline results from HARDIC and is the first to conduct a detailed analysis of cardiovascular health KAP/behaviour in an urbanising community of Nepal.

\section{METHODS}

\section{Ethical considerations}

The Nepal Health Research Council and the Institutional Review Board of Kathmandu Medical College approved this study. Following a pattern established at the outset of JD-HDSS, we consulted local leaders and sought their informal permission for HDSS activities. In addition, we periodically consulted with health and administrative authorities in both villages. All participants gave informed consent, and privacy was maintained during the interview process. To maintain confidentiality, all data were secured in the HDSS office. Computer data were accessible only to the research team. Although respondents received no monetary incentives, we provided a referral that included discounted consultation fees at Kathmandu Medical College or Nepal Medical College for self-reported illness and newly diagnosed hypertension.

\section{Study site}

We conducted our descriptive, community-based, crosssectional study between September and November 2011 in the JD-HDSS of Bhaktapur district in the Kathmandu Valley, $13 \mathrm{~km}$ from Kathmandu. An earlier report described the establishment of the surveillance site. ${ }^{20}$

\section{Study population and sample size}

This study is the first step in the larger HARDIC project that will be conducted in the whole JD-HDSS. Duwakot and Jhaukhel each contain nine administrative wards and we randomly selected three wards from each village. Based on the JD-HDSS 2010 baseline census, ${ }^{20}$ we compiled a complete list of households containing adults aged 25-59 years in the selected wards. Next, we selected one adult, of either sex, from all interview households and surveyed 789 of 840 households (non-response rate $=6.07 \%)$. We applied the Kish technique to select the respondent. $^{22}$

\section{Study tools}

We structured the basic questionnaire and tailored it to site-specific responses in Nepal using the WHO-NCD STEPwise approach to surveillance (STEPS; STEP 1 and 2 questionnaires) for demographic information, behavioural and physical measurements ${ }^{23}$ and other sources for addressing knowledge, attitude and practice/behaviour issues. ${ }^{15}$ 24-39 Responses to questions on cardiovascular health knowledge, attitude and practice/behaviour were given scores in order to compare and correlate the components. A detailed description of the scoring system is given as an online supplementary appendix to this article.

\section{Interviewers}

Twelve local female enumerators (two/ward) conducted the interviews. All enumerators had completed at least grade 10 in school. Supervisors included four public health graduates; a field co-ordinator with Master's and 
PhD degrees in public health; and two PhD students/ authors (AV and URA).

\section{Data collection}

\section{Interview process}

The interviews were conducted at the participants' homes. The initial part of the interview consisted of questions related to demographic profile. Questions then followed relating to knowledge of cardiovascular health (eg, causes and risk factors, warning signs and action for suspected heart attack); heart-healthy diet and disease prevention. The first two areas included unprompted (spontaneous, open-ended) and prompted (clues provided, close-ended) responses, and the latter two areas included only prompted responses. We asked respondents about their attitude towards different aspects of cardiovascular health: did they perceive themselves at risk for CVD? Did they think behaviour change would reduce their risk of developing GVD? The responses were recorded on a Likert scale (strongly agree, somewhat agree, do not know, somewhat disagree, strongly agree).

\section{Behavioural factors}

Behaviour-related questions were based on Step 1 of the WHO STEPS, which uses a questionnaire to collect data on risk factors. ${ }^{23}$ Our questions probed current and past smoking behaviour; smokeless tobacco; alcohol consumption in the last 30 days (current drinker) and drinking frequency among current drinkers. The physical activity section asked respondents to report the number of days and amount of time they participated in vigorous and moderate activities at work, leisure and travel. Additional practice and behavioural questions explored whether participants had engaged in any heart-friendly behaviour in the previous year and for what reason.

\section{Physical measurements}

Enumerators recorded anthropometric measurements (ie, weight, height, and waist and hip circumferences) according to the STEPs guidelines. ${ }^{23}$ Weight was measured to one decimal place using a Microlife BR-9201 Weighing Scale (Microlife AG Swiss Corporation, Widnau, Switzerland). Height and waist and hip circumferences were measured using non-stretchable tapes (Jonson Tapes Ltd, New Delhi, India). Blood pressure was determined digitally by Microlife BP 3AP1-3E (Microlife AG Swiss Corporation, Widnau, Switzerland). Enumerators recorded three readings for each respondent, taken at 5-min intervals. We averaged the readings to attain the final blood pressure measurements.

\section{Diagnostic criteria for subclassification}

Respondents with a known history of hypertension (diagnosed cases) and those diagnosed during the study according to the Joint National Committee-VII ${ }^{40}$ were termed as having 'hypertension'.
Data management

Supervisors checked all completed questionnaires and, if necessary, asked enumerators to revisit households. After omitting incomplete questionnaires, we included 777 individuals in the analysis. Except for missing recordings for height, weight or blood pressure, the data reported in our KAP study covers all 777 respondents. We outsourced data entry to a team of data entry operators, public health graduates by qualification. Data were coded and entered in Epidata V.2.1.

\section{Statistical analyses}

Data were analysed with SPSS V.17.0 (IBM, Armonk, New York, USA) and STATA V.10.0 (StataCorp, Texas, USA). After calculating the Metabolic Equivalent of Task minutes/week, we grouped participants as highly active, moderately active or inactive (low physical activity) in accord with the STEPS manual.

For scoring KAP/behaviour questions and to compare and correlate the three components, we scored responses regarding $\mathrm{KAP} /$ behaviour for cardiovascular health. The maximum possible scores for KAP/behaviour were 53, 56 and 25, respectively. Further, total knowledge score was classified into the following five categories based on the quintile scores: $\leq 20 \%$ 'highly insufficient'; 21-40\% 'insufficient'; 41-60\% 'sufficient'; 61$80 \%$ 'satisfactory'; $>80 \%$ 'highly satisfactory'. ${ }^{41}$

Categorical data are presented as numbers and percentages, and continuous data as the median and interquartile range (IQR). KAP percentage scores are presented as the median. We used the $\chi^{2}$ test to compare proportions among demographic variables and the Mann-Whitney U test to compare scores from men and women. $\mathrm{p}<0.05$ was considered to be statistically significant.

Cronbach's $\alpha$, which measures question reliability, for the overall knowledge and attitude was 0.941 (range: $0.775-0.913$ ) and 0.824 (range: $0.791-0.822$ ), respectively. Cronbach's $\alpha$ for practice and behaviour ranged from low (0.257) for physical activity questions to high (0.929) for blood pressure measurements.

\section{RESULTS}

\section{Demographic characteristics and cardiovascular} risk factors

Table 1 describes the sex-wise demographic characteristics of the respondents. Seventy per cent of all participants were women, and 25\% lacked formal education. The median age (IQR) for male and female respondents was 40 (33-49) years and 38 (32-46) years, respectively. Two-thirds of the female respondents were housewives and three of five men were either serviceholders or self-employed. We have shown previously that $59.2 \%$ belonged to the upper-lower class. ${ }^{20}$

Figure 1 shows the sex-wise prevalence of cardiovascular risk factors in the study population. Overall, 3 in 10 respondents were past or current smokers and 1 in 5 
Table 1 Demographic characteristics of the study population

\begin{tabular}{|c|c|c|c|}
\hline Demographic variables & $\begin{array}{l}\text { Male }(n=229) \\
\text { Number }(\%)\end{array}$ & $\begin{array}{l}\text { Female }(n=548) \\
\text { Number }(\%)\end{array}$ & $\begin{array}{l}\text { Total }(n=777) \\
\text { Number }(\%) \\
\end{array}$ \\
\hline \multicolumn{4}{|l|}{ Age (years) } \\
\hline $25-34$ & $69(26.8)$ & $188(73.2)$ & $257(100)$ \\
\hline $35-44$ & 78 (27.9) & $202(72.1)$ & $280(100)$ \\
\hline $45-59$ & $82(34.2)$ & $158(65.8)$ & $240(100)$ \\
\hline \multicolumn{4}{|l|}{ Caste/ethnicity } \\
\hline Brahmin & 85 (28.9) & $209(71.1)$ & $294(100)$ \\
\hline Chhetri & $55(28.4)$ & $139(71.6)$ & $194(100)$ \\
\hline Newar & $67(34.5)$ & $127(65.5)$ & $194(100)$ \\
\hline Others $^{*}$ & $22(23.2)$ & $73(76.8)$ & $95(100)$ \\
\hline \multicolumn{4}{|l|}{ Education } \\
\hline No formal schooling & 27 (12.9) & $182(87.1)$ & $209(100)$ \\
\hline Primary school (Grade:1-5) & $74(30.1)$ & $172(69.9)$ & $246(100)$ \\
\hline Secondary school (Grades: 6-10) & $74(37.4)$ & $124(62.6)$ & $198(100)$ \\
\hline Higher secondary and above (Grade: 11 and above) & $54(43.5)$ & $70(56.5)$ & $124(100)$ \\
\hline \multicolumn{4}{|l|}{ Major occupationt } \\
\hline Service (government and private) & $70(60.3)$ & $46(39.7)$ & $116(100)$ \\
\hline Self-employed & $72(66.7)$ & 36 (33.3) & $108(100)$ \\
\hline Agriculture & $48(38.1)$ & 78 (61.9) & $126(100)$ \\
\hline Housewife & $\mathrm{N} / \mathrm{A}$ & $369(100)$ & $369(100)$ \\
\hline Others§ & $39(67.2)$ & $19(32.8)$ & $58(100)$ \\
\hline
\end{tabular}

respondents had consumed at least one alcoholic beverage in the previous month. More than $40 \%$ of the respondents reported low physical activity. The prevalence of known and newly diagnosed hypertension was $21.6 \%$. As measured by body mass index (BMI), the prevalence of overweight and obesity was $29.7 \%$ and $9.4 \%$, respectively.

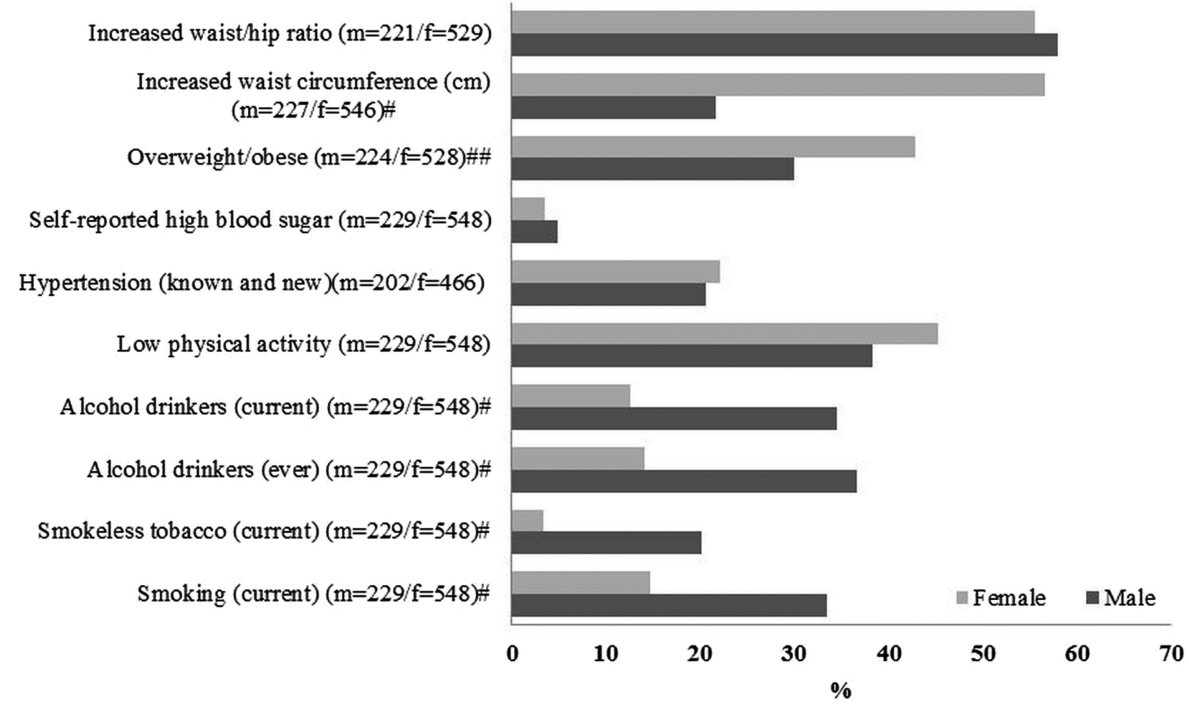

Figure 1 Sex-wise distribution of cardiovascular risk factor status in the study population. $m$, Number of males; $f$, number of females; \# $\mathrm{p}<0.001$, \#\# p<0.01 ( $\chi^{2}$ tests). Risk factor categories were based on the WHO-NCD Risk Factor STEPS Survey manual. ${ }^{23}$ Current smokers included those who responded 'yes' to 'Do you smoke?' Past smokers included those who replied 'yes' to 'Did you ever smoke in the past?'. 'Ever drinkers' included respondents who had 'consumed a drink that contained alcohol ever in lifetime,' and current drinkers included respondents who had 'consumed alcohol within the previous month.' The percentage of drinking frequency represents current drinkers who consumed at least one standard drink per occasion. Blood pressure data exclude respondents who did not submit to all three readings. Likewise, data for BMI, waist circumference and waist-hip ratio exclude respondents whose weight, height and waist and/or hip measurements were not taken. Increased waist circumference includes waist measurements of $\geq 80 \mathrm{~cm}$ (women) and $\geq 90 \mathrm{~cm}$ (men); increased waist-hip ratio is $\geq 0.85$ (women) and $\geq 0.90$ (men). 
Abdominal obesity (ie, increased waist circumference and waist-hip ratio) was $46.3 \%$ and $56.3 \%$, respectively. There was a statistically significant difference in the prevalence rate among men and women in smoking, smokeless tobacco use, alcohol intake, overweight/obesity and increased waist circumference.

\section{Knowledge towards CVD}

Knowledge regarding causes and warning signs of heart disease

Table 2 shows unprompted responses for the perceived causes of heart diseases. The responses ranged from $1 \%$ for high blood sugar to $29.1 \%$ for smoking. The median percentage scores for men and women were $13.8 \%$ and $10.4 \%$, respectively $(\mathrm{p}<0.001$, Mann-Whitney $\mathrm{U}$ test $)$. Younger respondents (<35 years) knew more than older participants (median $13.7 \%$ vs $10.3 \%, \mathrm{p}=0.01$ ). Respondents belonging to Brahmin, Newer and Chhetri ethnicities had less knowledge than those in the other caste/ethnicity group (median $13.8 \%$ vs $6.9 \%, \mathrm{p}=0.001$ ) (table 1). Respondents with high school or more education and working in government or non-government offices knew more than those with less education and in other employment situations (median $17.2 \%$ vs $10.34 \%$, $\mathrm{p}=0.001)$.

Table 2 also describes the warning signs of heart attack as perceived by the respondents. Around $60 \%$ of respondents did not know any of the heart attack signs. Among those who were familiar with those signs, nearly
$50 \%$ of respondents knew only one sign, $37 \%$ knew any two signs, $11.42 \%$ knew any three signs and $2.53 \%$ knew four signs. The proportions of each warning sign told by the male and female respondents were not statistically different $(p>0.05)$. The proportions of knowledge about warming signs were not statistically different in terms of age $\left(\chi^{2}=3.39, \mathrm{p}=0.49\right)$, caste $/$ ethnicity $\left(\chi^{2}=6.25, \mathrm{p}=0.4\right)$ and education $\left(\chi^{2}=5.50, \mathrm{p}=0.53\right)$. Importantly, only $20 \%$ of respondents identified chest pain-the most prominent and important indicator of heart attack-as a symptom of heart attack.

\section{Knowledge on action in case of a heart attack}

When asked about what action the respondents would take for a suspected heart attack, more than $20 \%$ gave no response and $75 \%$ (81.2\% men and $73 \%$ women, $\left.\chi^{2}=4.05, \mathrm{p}=0.04\right)$ said they would immediately take the affected person to hospital. About $3 \%$ said that they would try home therapy, consult a traditional healer or stay home and wait for the symptoms to go away.

\section{Knowledge on healthy foods for heart diseases}

When asked to identify a particular heart-healthy food, most respondents identified green-leafy vegetables $(94.6 \%)$ and fruit $(92.1 \%)$. Furthermore, 22\% thought salty food like chips and around $7 \%$ thought fried food or saturated fat (eg, ghee) are healthy foods.

Table 2 Percentage of respondents citing various causes of cardiovascular disease and warning signs of heart attack

\begin{tabular}{|c|c|c|c|c|}
\hline Causes of heart attack & $\begin{array}{l}\text { Male }(n=229) \\
\text { Number }(\%)\end{array}$ & $\begin{array}{l}\text { Female }(n=548) \\
\text { Number }(\%)\end{array}$ & $\begin{array}{l}\text { Total }(n=777) \\
\text { Number }(\%)\end{array}$ & p Value ${ }^{\star}$ \\
\hline Hypertension & $43(18.8)$ & 60 (10.9) & 103 (13.3) & $<0.01$ \\
\hline High blood sugar & $3(1.3)$ & $5(0.9)$ & $8(1.0)$ & 0.06 \\
\hline High cholesterol & $47(20.5)$ & $74(13.5)$ & $121(15.6)$ & 0.01 \\
\hline Physical inactivity & $16(7.0)$ & $22(4.0)$ & $38(4.9)$ & 0.08 \\
\hline Overweight & $13(5.7)$ & $29(5.3)$ & $42(5.4)$ & 0.82 \\
\hline Cigarette/bidi smoking & $80(34.9)$ & $147(26.8)$ & $227(29.1)$ & 0.02 \\
\hline Smokeless tobacco & $19(8.3)$ & $26(4.7)$ & $45(5.8)$ & 0.06 \\
\hline Excessive alcohol & $72(31.4)$ & $131(23.9)$ & $203(26.1)$ & 0.03 \\
\hline \multirow[t]{2}{*}{ Excess stress } & 37 (16.2) & $74(13.5)$ & $111(14.3)$ & 0.34 \\
\hline & $\begin{array}{l}\text { Male }(n=93) \dagger \\
\text { Number }(\%)\end{array}$ & $\begin{array}{l}\text { Female }(n=222) \dagger \\
\text { Number }(\%)\end{array}$ & $\begin{array}{l}\text { Total }(n=315) \dagger \\
\text { Number }(\%)\end{array}$ & p Value* \\
\hline Difficulty in breathing & $17(11.1)$ & $41(15.1)$ & $58(13.6)$ & 0.25 \\
\hline Pain in the chest & $30(19.6)$ & $57(21.0)$ & $87(20.5)$ & 0.74 \\
\hline Pain or numbness in the arms & $0(0)$ & $3(1.1)$ & $3(0.7)$ & - \\
\hline Pain in the teeth or jaw & $0(0)$ & $1(0.4)$ & $1(0.2)$ & - \\
\hline Excessive sweating & $15(9.8)$ & $30(11.0)$ & $45(10.6)$ & 0.69 \\
\hline Vomiting tendency & $1(0.7)$ & $6(2.2)$ & $7(1.6)$ & 0.65 \\
\hline Dizziness or light-headedness & $24(15.7)$ & $40(14.7)$ & $64(15.1)$ & 0.78 \\
\hline Loss of consciousness & $55(35.9)$ & $86(31.6)$ & $141(33.2)$ & 0.36 \\
\hline
\end{tabular}




\section{Attitudes and practice towards CVD}

Attitude towards heart health in an urbanising community

Table 3 describes opinions reflecting attitudes towards various aspects on heart diseases. Regarding lifestyle and preventive measures, $25 \%$ of men and $30 \%$ of women perceived themselves to be at risk of CVD. More than half of the respondents did not want to change their current lifestyle $(64.6 \%$ men vs $55.4 \%$ women, $\mathrm{p}<0.01)$. Nearly $23 \%$ said that they ate more and would like to cut down; approximately $82 \%$ considered themselves to be overweight, the perceived proportion being significantly higher among men $(\mathrm{p}<0.05)$; nearly $32 \%$ believed that they did not have time to take care of themselves; and three-fifths did not think that changing their behaviour would lower their cardiovascular risk. Further, $25.3 \%$ of men and $27.2 \%$ of women thought that God or a higher power determined their health.

Table 3 also describes the respondents' opinions on various preventive aspects of heart health that would be helpful. Almost all respondents believed that increased access to fruits, vegetables and other healthy foods would be helpful. Nearly 9 in 10 respondents thought that greater access to indoor and outdoor public recreational facilities would be helpful. Four per cent of respondents did not believe that smoking bans would be helpful to reduce heart diseases. Eight in 10 male respondents believed that local volunteers should try to change any adverse health behaviours while nearly 9 in 10 women believed the same $(\mathrm{p}<0.01)$.

\section{Practice towards heart diseases}

Half of all the respondents had their blood pressure measured and $10 \%$ reported getting a diagnostic test for CVD in the previous year. About $60 \%$ attempted to reduce their consumption of unhealthy foods and $25 \%$ tried to lose weight or increase physical activity. Half of the smokers said that they had attempted to quit smoking.

When enumerators asked the respondents who reported one or more positive health behaviours the main reason for trying to change their lifestyle or practice/behaviour, the reasons given were: they wanted to feel better $(70 \%)$; had seen, read or heard information $(65.4 \%)$; did it for their family $(45.9 \%)$; or were encouraged to do so by a healthcare professional (41.3\%), family member $(39 \%)$ or friend $(31.8 \%)$. Other reasons for changing lifestyle or practice/behaviour included wanting to avoid taking medications $(20.6 \%)$; a family

Table 3 Responses to attitude-related questions on cardiovascular disease

\begin{tabular}{|c|c|c|c|c|c|}
\hline SN & Items & $\begin{array}{l}\text { Male } \\
\text { Number } \\
(\%)\end{array}$ & $\begin{array}{l}\text { Female } \\
\text { Number } \\
(\%)\end{array}$ & $\begin{array}{l}\text { Total } \\
\text { Number } \\
(\%)\end{array}$ & p Value* \\
\hline \multicolumn{6}{|c|}{ Attitude items on heart health } \\
\hline 1 & I don't perceive myself to be at risk for heart disease $(m=225 / f=540) \dagger$ & $58(25.8)$ & 167 (30.9) & $225(29.0)$ & 0.15 \\
\hline 2 & $\begin{array}{l}\text { I don't want to change my lifestyle (activity, smoking, alcohol) } \\
(\mathrm{m}=229 / \mathrm{f}=548)\end{array}$ & $148(64.6)$ & $298(54.4)$ & $446(57.4)$ & $\mathrm{p}<0.01$ \\
\hline 3 & $\begin{array}{l}\text { I feel the amount of food I eat is too much, and I would like to cut } \\
\text { down }(m=229 / f=543) \dagger\end{array}$ & $35(15.2)$ & $140(25.5)$ & $175(22.5)$ & $\mathrm{p}<0.01$ \\
\hline 4 & I feel my present weight is too high for my health $(m=229 / f=548)$ & $37(14.9)$ & $130(23.7)$ & $167(21.5)$ & 0.02 \\
\hline 5 & $\begin{array}{l}\text { I don't think changing my behaviour will reduce my risk of developing } \\
\text { heart disease }(m=229 / f=522) \dagger\end{array}$ & $145(63.3)$ & $312(56.9)$ & $457(58.8)$ & 0.23 \\
\hline 6 & I don't have time to take care of myself $(m=229 / f=548)$ & 77( & 16 & (31.5) & 0.42 \\
\hline 7 & God or a higher power ultimately determines my health $(m=229 / f=548)$ & $58(25.3)$ & $149(27.2)$ & $207(26.6)$ & 0.59 \\
\hline \multicolumn{6}{|c|}{ Opinions on various preventive aspects of heart health that are helpful } \\
\hline 8 & $\begin{array}{l}\text { Access to more fruits, vegetables and other healthy foods } \\
(m=229 / f=548)\end{array}$ & $226(98.6)$ & $533(99.1)$ & $759(99.1)$ & $-\ddagger$ \\
\hline 9 & $\begin{array}{l}\text { Greater access to indoor and outdoor public recreational facilities } \\
(m=229 / f=548)\end{array}$ & $200(87.3)$ & $492(89.7)$ & $692(89.1)$ & 0.31 \\
\hline 10 & Smoking bans $(m=218 / f=535) \dagger$ & $209(96.1)$ & $515(96.2)$ & $724(96.1)$ & 0.89 \\
\hline 11 & More awareness programmes for a healthy & $214(96.1)$ & $483(90.1)$ & $697(98.0)$ & 0.38 \\
\hline 12 & $\begin{array}{l}\text { Availability of health facilities to detect and treat heart diseases } \\
(m=226 / f=531) \dagger\end{array}$ & $217(96.1)$ & $524(98.6)$ & $741(97.9)$ & 0.02 \\
\hline 13 & $\begin{array}{l}\text { Local volunteers who shall try to change any adverse health } \\
\text { behaviour }(m=226 / f=530) \dagger\end{array}$ & $186(82.1)$ & $522(98.5)$ & $708(93.6)$ & $\mathrm{p}<0.01$ \\
\hline \multicolumn{6}{|c|}{$\begin{array}{l}\text { *Obtained from a } \chi^{2} \text { test. } \\
\dagger ‘ \text { I do not know/cannot say' answers were excluded from the analysis. } \\
\text { †Cannot be computed due to the expected frequency being less than } 5 \text {. } \\
\text { m=number of males, f=number of females. Questions based on a } 5 \text {-scale Likert questions (strongly disagree, somewhat disagree, I do not } \\
\text { know, somewhat agree and strongly agree (question } 1-7) / v e r y \text { helpful; somewhat helpful; I do not know; not very helpful; not at all helpful } \\
\text { (question 8-13). We classified five options into three categories as 'agree/helpful', 'disagree/not helpful' and 'I do not know'. Only 'strongly } \\
\text { agree' or 'very helpful' and 'agreed/somewhat helpful' answers were merged and presented in the table and 'I do not know/cannot say' were } \\
\text { excluded from the analysis. }\end{array}$} \\
\hline
\end{tabular}


member, relative or friend who developed CVD, became ill or died (16.5\%); and developing possible cardiovascular symptoms $(14.8 \%)$.

\section{Comparison between level of knowledge, attitude and behaviour/practice}

Overall, the average prompted knowledge of heart diseases (median $79.3 \%$ ) was $11.5 \%$ lower than the average attitudes (median $67.8 \%$ ) and nearly $31.1 \%$ higher than the average practices (median $48.2 \%$ ). Next, the average level of attitude scores was nearly $19.6 \%$ higher than that for practices. Similarly, the average spontaneous knowledge of heart diseases (median 10.3\%) was 57.5\% lower than the average attitudes (median 67.8\%) and nearly $40 \%$ lower than the average practices (median $48.18 \%)$.

Table 4 describes the level of KAP based on quintile scores. Regarding knowledge, $20.4 \%$ of the respondents had highly insufficient knowledge, 23.2\% had insufficient knowledge, $22.6 \%$ had sufficient knowledge, $16.5 \%$ had satisfactory knowledge and $17.2 \%$ had highly satisfactory knowledge. Similarly, attitude levels were as follows: highly insufficient $20.6 \%$, insufficient $26.9 \%$; sufficient $15.4 \%$; satisfactory $11.2 \%$ and highly satisfactory $19.8 \%$. Regarding behaviour/practices, it was highly insufficient in $12.1 \%$ of the respondents, insufficient in $24.3 \%$; sufficient in $22.7 \%$; satisfactory in $27.5 \%$ and highly satisfactory in $13.4 \%$. Among those with highly insufficient knowledge, $20.3 \%$ of them had highly satisfactory attitudes and $6.9 \%$ had highly satisfactory practices. Conversely, among the respondents with highly satisfactory knowledge, $14.7 \%$ had highly satisfactory attitude and $19.5 \%$ and $13.9 \%$ had satisfactory and highly satisfactory practices, respectively. Likewise, 1 in 10 respondents with satisfactory knowledge had a satisfactory attitude while 2 in 10 had a highly satisfactory attitude. Nearly 4 of 10 had satisfactory/highly satisfactory behaviour. As the level of knowledge increased, the highly satisfactory practice also increased from $6.9 \%$ to $13.4 \%$. However, when the level of knowledge increased, the highly satisfactory attitude decreased from $20.3 \%$ to $14.7 \%$.

Regarding attitude, among those with the level of attitudes of highly insufficient, $41.2 \%$ had satisfactory/ highly satisfactory behaviour/practice. When the level of attitude was highly satisfactory, 35\% had satisfactory/ highly satisfactory practice. Similarly, when the attitude was sufficient, $25 \%$ had insufficient practice and nearly $41 \%$ had satisfactory practice. When the level of attitude increased, the proportion of those with highly satisfactory practice remained unchanged.

A comparison of male and female respondents showed no difference in the level of knowledge $\left(\chi^{2}=4.4\right.$, $\mathrm{p}=0.4)$, attitudes $\left(\chi^{2}=3.6, \mathrm{p}=0.5\right)$ and practice $\left(\chi^{2}=2.1\right.$,

Table 4 Percentage distribution of the level of knowledge, attitude and behaviour/practice regarding cardiovascular health

\begin{tabular}{|c|c|c|c|c|c|}
\hline \multirow[b]{2}{*}{ Knowledge $(n=777)$} & \multicolumn{5}{|c|}{ Attitude ( $\mathrm{n}=777$ ) } \\
\hline & $\mathrm{HI}(\mathrm{n}=160)$ & $I(n=209)$ & Suff $(n=120)$ & Sat $(n=134)$ & HS (n=154) \\
\hline $\mathrm{HI}(\mathrm{n}=159)$ & 26.0 & 27.6 & 13.8 & 12.5 & 20.3 \\
\hline I $(n=180)$ & 17.9 & 28.4 & 19.1 & 12.5 & 22.2 \\
\hline Suff $(n=176)$ & 17.9 & 29.8 & 17.2 & 11.9 & 26.2 \\
\hline Sat $(n=128)$ & 20.8 & 33.7 & 15.8 & 6.9 & 23.8 \\
\hline \multirow[t]{2}{*}{ HS $(n=134)$} & 33.7 & 24.2 & 12.6 & 12.6 & 14.7 \\
\hline & \multicolumn{5}{|c|}{ Behaviour $(\mathrm{n}=777)$} \\
\hline Knowledge $(n=777)$ & $\overline{H I}(n=94)$ & $I(n=189)$ & Suff $(n=176)$ & Sat $(n=214)$ & HS $(n=104)$ \\
\hline $\mathrm{HI}(\mathrm{n}=159)$ & 16.4 & 29.6 & 21.4 & 25.8 & 6.9 \\
\hline I $(n=180)$ & 10.4 & 26.1 & 19.4 & 30.6 & 13.3 \\
\hline Suff $(n=176)$ & 11.4 & 20.5 & 20.5 & 31.2 & 16.5 \\
\hline Sat $(n=128)$ & 10.9 & 18.8 & 33.6 & 19.5 & 17.2 \\
\hline \multirow[t]{2}{*}{ HS $(n=134)$} & 11.2 & 26.1 & 20.9 & 28.5 & 13.4 \\
\hline & \multicolumn{5}{|c|}{ Behaviour $(\mathrm{n}=777)$} \\
\hline Attitude ( $n=777)$ & $\overline{\mathrm{HI}}$ & $\mathbf{I}$ & Suff & Sat & HS \\
\hline $\mathrm{HI}(\mathrm{n}=132)$ & 15.0 & 23.8 & 20.0 & 28.1 & 13.1 \\
\hline I $(n=101)$ & 12.0 & 22.0 & 18.7 & 30.1 & 17.2 \\
\hline Suff $(n=256)$ & 10.0 & 24.2 & 25.0 & 28.3 & 12.5 \\
\hline Sat $(n=134)$ & 13.8 & 33.3 & 17.2 & 29.9 & 5.7 \\
\hline HS $(n=154)$ & 10.4 & 20.8 & 33.8 & 24.0 & 11.0 \\
\hline
\end{tabular}

HI, highly insufficient; HS, highly satisfactory; I, insufficient; Sat, satisfactory; Suff: sufficient.

The total scores were 53, 64 and 25 for KAP, respectively. Then the quintile scores were obtained. The quintile scores (first-fourth) were for prompted knowledge: $34,40,43,45$; for attitudes: 33, 37, 39, 42; for behaviour: 9, 11, 13, 15. Next, the levels of survey respondents on KAP were classified into the following five subdivisions based on the quintile score: $\leq 20 \%$ 'highly insufficient'; $21-40 \%$ 'insufficient'; $41-60 \%$ 'sufficient'; $61-80 \%$ 'satisfactory'; $>80 \%$ 'highly satisfactory'. ${ }^{41}$ The median percentage scores for KAP were $79.3,74.2$ and 48 for all respondents. 
$\mathrm{p}=0.7)$. However, there were significant differences in the level of knowledge according to age $\left(\chi^{2}=18.1\right.$, $\mathrm{p}=0.02)$, caste/ethnicity $\left(\chi^{2}=43.8, \mathrm{p}<0.001\right)$ and education level $\left(\chi^{2}=48.7, p<0.001\right)$. In contrast, the level of attitude was not statistically significant for these variables $(\mathrm{p}>0.05)$. On the other hand, the level of practice was also statistically different according to age $\left(\chi^{2}=18.7\right.$, $\mathrm{p}=0.01)$, caste $/$ ethnicity $\left(\chi^{2}=21.1 ; \mathrm{p}=0.004\right)$ and educational status $\left(\chi^{2}=45.7, \mathrm{p}<0.001\right)$.

Respondents $<35$ years of age were more likely to have highly satisfactory knowledge $(37.3 \%$ vs $29.2 \%)$ and practice $(38.5 \%$ vs $19.2 \%)$ than those $>45$ years. Brahmins $(30.5 \%)$ were more likely to have highly satisfactory knowledge than Newars (27.6\%), Chhetris $(20.4 \%)$ and others $(21.5 \%)$. Regarding highly satisfactory practice, the proportion was highest among Brahmins (41.3\%), followed by Chhetris (30.8\%), Newars $(17.3 \%)$ and others $(10.6 \%)$. Those who had no formal schooling exhibited a higher proportion of highly satisfactory knowledge than those who had high school or more education $(28.3 \%$ vs $24.6 \%$, but highly satisfactory practice was low among them $(12.5 \%$ vs $28.8 \%$, data not shown).

\section{DISCUSSION}

The present study is the first to conduct a detailed analysis of the relationship between $\mathrm{KAP} /$ health literacy and cardiovascular health in a semiurban setting near Kathmandu.

\section{Cardiovascular risk factors are abundant in the study population}

Our respondents showed a high burden of behavioural and biological risk factors. While the prevalence of tobacco smoking was similar to the national average, the alcohol consumption was lower. ${ }^{42}$ National figures on tobacco smoking and alcohol consumption for Bangladesh, Nepal, India and Pakistan show that current smoking of any tobacco product (age-standardised rate, both sexes) is $24 \%, 32 \%, 15 \%$ and $20 \%$, respectively. ${ }^{19}$ The total adult (recorded and unrecorded) per capita consumption of pure alcohol according to the WHO-available projected estimates for 2008 indicates that consumption in Bangladesh, Nepal, India and Pakistan is $0.17,2.42,2.69$ and $0.05 \mathrm{~L}$ of pure alcohol, respectively, over a calendar year. ${ }^{19}$ The numbers have been increasing in these countries over the last few years. $^{19}$

In accord with our earlier review on obesity in Nepal, the effect of urbanisation is evident in low physical activity and overweight/obesity that exceeds the national average. ${ }^{21} 42$ The prevalence of hypertension in our study population is similar to the national average $(22 \%)$ but less by about one-third than a study in Bhadrabas, a similar semiurban Kathmandu community, ${ }^{43}$ most probably due to the different age groups. The 2008 national reported age-standardised level of hypertension in Nepal is similar to levels in Bangladesh but lower than in Pakistan $(38.6 \%$ and $39.5 \%$, respectively) and higher than in India $(35.2 \%) .{ }^{44}$ Self-reported prevalence of diabetes mellitus $(3.9 \%)$ confirms the JD-HDSS baseline figure reported earlier. ${ }^{20}$

\section{Knowledge of cardiovascular health is limited}

Our study population showed low overall knowledge of the causes of CVD. Unprompted responses suggested that respondents identified behavioural factors (eg, smoking) more frequently than physiological causes (eg, hypertension). Other studies have reported similar findings for unprompted $^{38}$ and prompted responses. $^{33}$ Conversely, unhealthy diet, obesity and family history were common responses in Taiwan. ${ }^{31}$ In Vietnam, knowledge on the negative influence of tobacco smoking on stroke and heart attack is lower than general knowledge regarding health risks of active smoking and exposure to second-hand smoke. ${ }^{45}$

Many of our respondents also attributed CVD to environmental factors such as food hygiene and air pollution. Indeed, acute inflammatory reactions to air pollutants accelerate coronary atherosclerosis and trigger arrhythmia or myocardial infarction. ${ }^{46}$ Unlike the Strong Heart Study $^{39}$ in American populations, our results did not exhibit a higher probability of knowledge of a risk factor in persons who have that risk factor, demonstrating poor cardiovascular health literacy even among those already affected.

Similar to Pakistan, ${ }^{15}$ a large majority $(60 \%)$ of our respondents could not identify even one heart attack symptom. However, similar to an earlier study in Nepal, ${ }^{16}$ 6-22\% of individuals in our demographic subsets recognised chest pain as a symptom, which is less compared with $60 \%$ of Vietnamese Americans who spontaneously mentioned chest pain. ${ }^{47}$ Importantly, two-thirds of heart attack patients delayed their arrival at a Karachi hospital because they did not recognise heart attack symptoms. ${ }^{15}$ Similar to a previous study, ${ }^{18}$ three quarters of our respondents believed they would immediately take a suspected heart attack patient to a hospital, but one-fifth did not answer the question or opted instead for home therapy or traditional healing. Combined with our earlier finding of not knowing heart attack symptoms, this lack of knowledge about appropriate action underscores the need to educate the Nepalese population about this issue. In contrast, $85 \%$ of Vietnamese Americans knew that they should immediately call 911 if they suspected a heart attack. ${ }^{45}$ Despite inadequate knowledge about the causes of CVD, our respondents were much better informed about preventive measures. This finding concurs with the perception level of American women, ${ }^{35}$ probably because enumerators asked prompted questions in this section of the questionnaire. In Taiwan, only $25 \%$ of respondents thought that CVD was preventable and $50 \%$ were 'not sure.'31 
Inappropriate attitude towards cardiovascular health

In contrast to their opinion that behavioural modifications can prevent CVD, most of our respondents did not consider themselves at risk and did not want to alter their lifestyle. This may be explained by the Health Belief Model. ${ }^{48}$ Others have described a similarly optimistic bias. ${ }^{49}$ Risk indicators (eg, number of cigarettes smoked; death of a parent due to CVD and selfassessment of blood pressure, weight and cholesterol levels) account for a $24 \%$ variance in perceived risk. ${ }^{49}$ The likelihood of perceiving oneself at higher risk increases when the presence of a risk factor is known. ${ }^{31}$ However, respondents often underestimate their cardiovascular risk. ${ }^{49}$

\section{Attempts for better cardiovascular health practice/behaviour}

Compared with Nepal's national average (69\%), only half of our respondents underwent blood pressure measurement in the previous year. ${ }^{42}$ Ninety per cent of the known hypertensive population had their blood pressure under control, exceeding the $6 \%$ and $9.5 \%$ control rate reported in two other suburban Kathmandu studies 4350 and an urban study in Eastern Nepal $(58.5 \%) .{ }^{51}$ Half of the smokers reported here that they had tried to quit smoking. Our questionnaire did not explore whether they had actually quit and did not identify the barriers against quitting, information that might be important for public health. The theory of reasoned action ${ }^{48}$ argues that intention is a critical component of healthy behaviour. Although confirming that the genuineness of intention is difficult, such intention may provide an opportunity for public health intervention. Importantly, we identified our respondents' reasons for attempting positive health behaviour. Many constructs of the Health Belief Model, ${ }^{48}$ such as perceived benefit ('wanted to feel better'), cues to action ('encouraged by a health professional, etc') and fear ('death of a family member, etc '), appear to affect behavioural decisions.

\section{Influence of gender}

Although women were unintentionally oversampled, our analysis includes a gender-wise stratification and we presented data separately whenever we observed marked gender differences. In our study, more men than women smoked tobacco or drank alcohol. The prevalence of hypertension and self-reported diabetes was similar in both groups. On the other hand, low physical activity and obesity were higher in the women. Although men had better knowledge of heart disease, their attitude was similar to those reported by women. However, more women than men strongly agreed that their health was ultimately determined by God or a higher power. Female gender is usually significantly related to good knowledge of CVD. ${ }^{52}$ One major factor for the gender discrepancy in our study is that more women $(33.2 \%)$ than men $(11.8 \%)$ lacked formal education, which in itself is alarming. In fact, illiteracy is one of the main risk factors along with behavioural factors in rural/ urban Asian Indian women. ${ }^{53}$

\section{Effect of other sociodemographic variables on KAP}

Age-wise, KAP/behaviour scores decreased around 4\% from the youngest to the oldest age group. An earlier study reported a higher level of knowledge among young respondents. ${ }^{36}$ Interestingly, a study in adolescents reported a very poor level of cardiovascular knowledge. ${ }^{54}$ Otherwise, knowledge levels rise linearly from childhood until middle age, when the level starts to plateau. ${ }^{55}$ In our study, better-educated respondents ate more fruit and consumed less tobacco and alcohol, but they also reported less physical activity and more hypertension. The highest education category (high school or more) scored higher than the lowest category (no formal schooling) but only by 3-8\%. Other studies observed a consistent link between better KAP scores and higher education. ${ }^{31} \quad 36 \quad 52 \quad 56$ Occupation-wise, employed respondents knew more about biological causes (eg, high blood pressure, diabetes and high cholesterol), possibly due to more education, wider exposure to information and better access to screening and treatment. A Canadian study reported similar findings. ${ }^{36}$

\section{Prompted versus unprompted responses}

Although we used unprompted responses to evaluate general knowledge, we used prompted responses to calculate scores, thus providing a denominator ('full marks') to calculate median score \%. In other settings, KAP studies have variably used prompted $33 \quad 394757$ or unprompted questions, ${ }^{16} 3138$ while some studies used both. ${ }^{35}$ Other studies did not identify their chosen method. ${ }^{32}$ Although the accuracy of prompted versus unprompted questions in knowledge assessment has been a topic of debate, prompted questions confer a higher level of knowledge. ${ }^{58}$ When we analysed knowledge responses based on prompted responses, the percentage of correct answers increased drastically. The psychological explanation is that respondents must simply 'recognise' answers to prompted questions, but they must engage in the more difficult mental process of 'recalling' answers to unprompted questions. ${ }^{59}$ We believe that unprompted responses more accurately reflect knowledge level because they emerge from a thought process that involves respondents' knowledge, experience and perception regarding a specific issue.

\section{Comparison between levels of KAP towards CVD}

The findings of the study indicate that there is a gap in knowledge attitude and practices. The poor relation between KAP scores was unsurprising because a linear relationship between variables may not exist in cardiovascular health (eg, highly satisfactory knowledge=high satisfactory attitude and behaviour). Valente argued that each of six possible behaviour change models contains a varying order of $\mathrm{KAP} /$ behaviour and that a population can be described in terms of the percentage that fits 
into each model. ${ }^{60}$ This implies that no universal intervention can improve the cardiovascular health KAP of every individual in a community. The challenge lies in identifying individuals who fit into different linear models. Furthermore, health behaviour theories (eg, social cognitive theory and the theory of reasoned action $)^{48}$ suggest that knowledge and attitude are only two components of the pathways that lead to behaviour. Constructs (eg, self-efficacy) and other personal and environmental factors (in social cognitive theory) and perceived behavioural control, subjective norms and ultimately intention (in the theory of reasoned action) play crucial roles in shaping one's health behaviour. ${ }^{48}$

\section{Study limitations}

Women were unintentionally oversampled $(72.7 \%)$, although the male: female ratio of the study population was $1: 1.15{ }^{20}$ Women were more likely to be available in the households when enumerators visited as most of the women in our study were housewives. The age-range was limited to $25-59$ years as the age groups $60-64$ and $70-$ 74 years only constituted 1-2\% of the total JD-HDSS population. Most of the respondents belonged to the caste/ethnic groups Brahmin, Chhetri and Newar, which are not representative of all caste/ethnic groups in Nepal. Further, respondents' and interviewers' mood, as well as place and time of interview, may affect the study. There is also the possibility of recall bias when questions are asked about history of CVD risk factors.

\section{CONCLUSION}

Our community-based cross-sectional HARDIC study demonstrated poor knowledge, inappropriate attitude and highly adverse behaviour regarding cardiovascular health in a semiurban community of Nepal even among those already affected by CVD. We aimed to determine a baseline KAP in the community to aid the planning of health promotion activities. Our results show the potential and possibility that community health promotion can improve cardiovascular health literacy.

\section{Author affiliations}

${ }^{1}$ Department of Community Medicine, Kathmandu Medical College, Kathmandu, Nepal

${ }^{2}$ Nordic School of Public Health NHV, Gothenburg, Sweden

${ }^{3}$ Department of Internal Medicine and Clinical Nutrition, Institute of Medicine, Sahlgrenska Academy at University of Gothenburg, Gothenburg, Sweden

Acknowledgements The authors are grateful to the study participants. We acknowledge all enumerators; field supervisors (Rachana Shrestha, Vishal Bhandari, Chandra Shova Khaitu and Shova Poudel); and our field coordinator, Professor Dr Muni Raj Chhetri. We thank scientific editor Karen Williams (Kwills Editing Services, Weymouth, MA, USA) for providing professional English-language editing of this article.

Contributors AV designed the study, performed statistical analysis and drafted the manuscript. URA performed statistical analysis and revised the manuscript. AK helped design the study and provided critical revision of the manuscript. All authors have read and approved the final manuscript.
Funding This study was supported by grants from the Wilhelm \& Martina Lundgren's Foundation (vet1-367/2011 and vet1-379/2012) and the University of Gothenburg, Sweden through a 'Global University' grant (A11 0524/09).

Competing interests None.

Ethics approval Nepal Health Research Council.

Provenance and peer review Not commissioned; externally peer reviewed.

Data sharing statement No additional data are available.

Open Access This is an Open Access article distributed in accordance with the Creative Commons Attribution Non Commercial (CC BY-NC 3.0) license, which permits others to distribute, remix, adapt, build upon this work noncommercially, and license their derivative works on different terms, provided the original work is properly cited and the use is non-commercial. See: http:// creativecommons.org/licenses/by-nc/3.0/

\section{REFERENCES}

1. Alwan A. Global status report on noncommunicable diseases 2010. Geneva: World Health Organization, 2011.

2. World Health Organization. Noncommunicable diseases in the South-East Asia Region: situation and response 2011. New Delhi: World Health Organization, Regional Office for South-East Asia, 2011.

3. Lozano R, Naghavi M, Foreman K, et al. Global and regional mortality from 235 causes of death for 20 age groups in 1990 and 2010: a systematic analysis for the Global Burden of Disease Study 2010. Lancet 2012;380:2095-128.

4. Reddy KS. Cardiovascular diseases in the developing countries: dimensions, determinants, dynamics and directions for public health action. Public Health Nutr 2002;5:231-7.

5. Reddy KS, Yusuf S. Emerging epidemic of cardiovascular disease in developing countries. Circulation 1998;97:596-601.

6. Engelgau MM, El-Saharty S, Kudesia P, et al. Capitalizing on the demographic transition: tackling noncommunicable diseases in South Asia. Washington, DC: World Bank Publications, 2011.

7. Ezzati M, Lopez AD, Rodgers A, et al. Comparative quantification of health risks: global and regional burden of disease attributable to selected major risk factors. Geneva: World Health Organization, 2004.

8. Khaw KT, Wareham N, Bingham S, et al. Combined impact of health behaviours and mortality in men and women: the EPIC-Norfolk prospective population study. PLoS Med 2008;5:e12.

9. Mendis S, Puska P, Norrving B. Global atlas on cardiovascular disease prevention and control. Geneva: World Health Organization, 2011.

10. Alwan A, Maclean DR, Riley LM, et al. Monitoring and surveillance of chronic non-communicable diseases: progress and capacity in high-burden countries. Lancet 2010;376:1861-8.

11. Mendis S, Alwan A. Prioritized research agenda for prevention and control of noncommunicable diseases. Geneva: World Health Organization, 2011.

12. Puska P. From Framingham to North Karelia: from descriptive epidemiology to public health action. Prog Cardiovasc Dis 2010;53:15-20.

13. Pearson TA, Bazzarre TL, Daniels SR, et al. American Heart Association guide for improving cardiovascular health at the community level: a statement for public health practitioners, healthcare providers, and health policy makers from the American Heart Association Expert Panel on Population and Prevention Science. Circulation 2003;107:645-51.

14. Lloyd-Jones DM, Hong Y, Labarthe D, et al. Defining and setting national goals for cardiovascular health promotion and disease reduction the American Heart Association's Strategic Impact Goal through 2020 and beyond. Circulation 2010;121:586-613.

15. Khan MS, Jafary FH, Faruqui AM, et al. High prevalence of lack of knowledge of symptoms of acute myocardial infarction in Pakistan and its contribution to delayed presentation to the hospital. BMC Public Health 2007;7:284.

16. Limbu YR, Malla R, Regmi SR, et al. Public knowledge of heart attack in a Nepalese population survey. Heart Lung 2006;35:164-9.

17. Upadhyay DK, Palaian S, Shankar PR, et al. Knowledge, attitude and practice about diabetes among diabetes patients in Western Nepal. Rawal Med J 2008;33:8-11.

18. Vaidya A. Tackling cardiovascular health and disease in Nepal: epidemiology, strategies and implementation. Heart Asia 2011;3:87-91. 
19. World Health Organization. Global Health Observatory Data Repository. http://apps.who.int/ghodata (accessed 28 Jun 2013).

20. Aryal UR, Vaidya A, Shakya-Vaidya S, et al. Establishing a health demographic surveillance site in Bhaktapur district, Nepal: initial experiences and findings. BMC Res Notes 2012;5:489.

21. Vaidya A, Shakya S, Krettek A. Obesity prevalence in nepal: public health challenges in a low-income nation during an alarming worldwide trend. Int J Environ Res Public Health 2010;7:2726-44.

22. Kish L. Sampling organizations and groups of unequal sizes. Am Sociol Rev 1965;30:564-72.

23. WHO STEPS Instrument (Core and Expanded): The WHO STEPwise approach to chronic disease risk factor surveillance (STEPS). http://www.who.int/chp/steps/STEPS_Instrument_v2.1.pdf

24. Lin W, Yang H, Hang $\mathrm{C}$, et al. Nutrition knowledge, attitude, and behavior of Taiwanese elementary school children. Asia Pac J Clin Nutr 2007;16:534-46.

25. Torabi MR, Yang J, Li J. Comparison of tobacco use knowledge, attitude and practice among college students in China and the United States. Health Promot Int 2002;17:247-53.

26. Kosaryan M, Vahidshahi K, Siami R, et al. Knowledge, attitude, and practice of reproductive behavior in Iranian minor thalassemia couples. Saudi Med J 2009;30:835-9.

27. Neamatollahi $\mathrm{H}$, Ebrahimi M, Talebi M, et al. Major differences in oral health knowledge and behavior in a group of Iranian pre-university students: a cross-sectional study. J Oral Sci 2011;53:177-84.

28. Sharda AJ, Shetty S. A comparative study of oral health knowledge, attitude and behaviour of first and final year dental students of Udaipur city, Rajasthan, India. Int J Dent Hyg 2008;6:347-53.

29. Yap J, Lee V, Yau T, et al. Knowledge, attitudes and practices towards pandemic influenza among cases, close contacts, and healthcare workers in tropical Singapore: a cross-sectional survey. BMC Public Health 2010;10:442.

30. Maimaiti N, Shamsuddin K, Abdurahim A, et al. Knowledge, attitude and practice regarding HIV/AIDS among University students in Xinjiang. Global J Health Sci 2010;2:51.

31. Chen W, Yu Y, Glaser K. The knowledge and attitudes of coronary heart disease prevention among middle and older aged people in a community in Taipei. Taiwan Geriatr Gerontol 2009;4:251-62.

32. Dodani S, Mistry R, Khwaja A, et al. Prevalence and awareness of risk factors and behaviours of coronary heart disease in an urban population of Karachi, the largest city of Pakistan: a community survey. J Public Health 2004;26:245-9.

33. Saeed O, Gupta V, Dhawan N, et al. Knowledge of modifiable risk factors of Coronary Atherosclerotic Heart Disease (CASHD) among a sample in India. BMC Int Health Hum Rights 2009;9:2.

34. Gazmararian JA, Williams MV, Peel J, et al. Health literacy and knowledge of chronic disease. Patient Educ Couns 2003;51:267-75.

35. Mosca L, Jones WK, King KB, et al. Awareness, perception, and knowledge of heart disease risk and prevention among women in the United States. Arch Fam Med 2000;9:506.

36. Potvin L, Richard L, Edwards AC. Knowledge of cardiovascular disease risk factors among the Canadian population: relationships with indicators of socioeconomic status. Can Med Assoc J 2000;162:S5-11.

37. Lim K, Sumarni M, Amal N, et al. Tobacco use, knowledge and attitude among Malaysians age 18 and above. Trop Biomed 2009;26:92-9.

38. Wong BM, Garcia Y, Barr A, et al. Cardiovascular risk factor awareness in a disadvantaged inner-city population-implications for preventive strategies. Can J Cardiol 2008;24:677-82.

39. Schweigman K, Eichner J, Welty TK, et al. Cardiovascular disease risk factor awareness in American Indian communities: the Strong Heart Study. Ethn Dis 2006;16:647.

40. Lenfant C, Chobanian AV, Jones DW, et al Seventh report of the Joint National Committee on the Prevention, Detection, Evaluation, and Treatment of High Blood Pressure (JNC 7). Circulation 2003;107:2993-4.

41. United Nations Children Fund. Baseline survey of the knowledge, attitude and practice (KAP) of parents/guardians on early childhood development and primary education in Nepal. Lalitpur, Nepal: UNICEF Nepal Country Office, 2009.

42. Ministry of Health and Population, Nepal. Nepal non-communicable diseases risk factors survey 2007. Kathmandu, Nepal: Ministry of Health and Population, Nepal, 2008.

43. Vaidya A, Pathak RP, Pandey MR. Prevalence of hypertension in Nepalese community triples in 25 years: a repeat cross-sectional study in rural Kathmandu. Indian Heart J 2012;64:128-31.

44. World Health Organization. WHO Risk Factor Database. https:// apps.who.int/infobase/Indicators.aspx (accessed 4 Aug 2013).

45. An DTM, Minh HV, Huong LT, et al. Knowledge of the health consequences of tobacco smoking: a cross-sectional survey of Vietnamese adults. Global HealthAction 2013;6:18707.

46. Brook RD, Franklin B, Cascio W, et al. Air pollution and cardiovascular disease A statement for healthcare professionals from the expert panel on population and prevention science of the American Heart Association. Circulation 2004;109:2655-71.

47. Nguyen TT, Liao Y, Gildengorin G, et al. Cardiovascular risk factors and knowledge of symptoms among Vietnamese Americans. J Gen Intern Med 2009;24:238-43.

48. Redding CA, Rossi S, Rossi R, et al. Health behavior models. Int Electron J Health Educ 2000;3:180-93.

49. Avis NE, Smith KW, McKinlay JB. Accuracy of perceptions of heart attack risk: what influences perceptions and can they be changed? Am J Public Health 1989;79:1608-12.

50. Sharma D, Bkc M, Rajbhandari S, et al. Study of prevalence, awareness, and control of hypertension in a suburban area of Kathmandu, Nepal. Indian Heart J 2006;58:34-7.

51. Vaidya A, Pokharel P, Karki P, et al. Exploring the iceberg of hypertension: a community based study in an eastern Nepal town. Kathmandu Univ Med J 2007;5:349-59.

52. Attarchi M, Mohammadi S, Nojomi M, et al. Knowledge and practice assessment of workers in a pharmaceutical company about prevention of coronary artery disease. Acta Med Iran 2012:50:697-703.

53. Pandey RM, Agrawal A, Misra A, et al. Population-based intervention for cardiovascular diseases related knowledge and behaviours in Asian Indian women. Indian Heart J 2012;65:40-7.

54. Vanhecke TE, Miller WM, Franklin BA, et al. Awareness, knowledge, and perception of heart disease among adolescents. Eur $J$ Cardiovasc Prev Rehabil 2006;13:718-23.

55. White CW, Albanese MA. Changes in cardiovascular health knowledge occurring from childhood to adulthood. A cross-sectional study. Circulation 1981;63:1110-15.

56. Yahya R, Muhamad R, Yusoff HM. Association between knowledge, attitude and practice on cardiovascular disease among women in Kelantan, Malaysia. Int $J$ Collaborative Res Intern Med Public Health 2012;4:1507-23.

57. Muhamad R, Yahya R, Yusoff HM, et al. Knowledge, attitude and practice on cardiovascular disease among women in North-Eastcoast Malaysia. Int J Collaborative Res Int Med Public Health 2012;4:85-98.

58. Waller J, McCaffery K, Wardle J. Measuring cancer knowledge: comparing prompted and unprompted recall. Br J Psychol 2004;95:219-34.

59. Glass AL, Holyoak KJ. Cognition. 2nd edn. New York: McGraw-Hill, 1986.

60. Valente TW, Paredes P, Poppe PR. Matching the message to the process the relative ordering of knowledge, attitudes, and practices in behavior change research. Hum Commun Res 1998;24:366-85. 